\title{
Progressive congenital emphysema detected in an elderly adult
}

\author{
Mario Fonseca-Paricio ${ }^{1}$, Phue Khaing ${ }^{2}$, Ena Gupta ${ }^{3}$, Gregory C. Kane ${ }^{* 2}$ \\ ${ }^{1}$ Department of Internal Medicine, Thomas Jefferson University, Philadelphia, Pennsylvania, United States \\ ${ }^{2}$ Department of Pulmonary, Allergy, \& Critical Care, Thomas Jefferson University, Philadelphia, Pennsylvania, United States \\ ${ }^{3}$ Department of Pulmonary and Critical Care, Einstein Medical Center, Philadelphia, Pennsylvania, United States
}

Received: January 12, 2020

DOI: $10.5430 /$ crim.v7n2p1
Accepted: April 14, 2020

Online Published: May 21, 2020

\begin{abstract}
Congenital emphysema is a rare congenital disease which typically manifests in infants and newborns. Even more unusual is detection in later adult life though this has been reported.
\end{abstract}

Key Words: Lobar emphysema, Bullous emphysema, Progressive congenital emphysema

\section{INTRODUCTION}

Congenital emphysema is a rare congenital disease which typically manifests in infants and newborns. Even more unusual is detection in later adult life though this has been reported.

\section{Case presentation}

We describe an 82-year-old woman with progressive dyspnea for one year. She has a history of asthma with fixed obstruction, hypertrophic cardiomyopathy and distant pulmonary embolism on anticoagulation. She was admitted to the hospital for an asthma exacerbation and noted to have hyperaeration in the left lower lobe with segmental bronchial narrowing on CT scan (see Figure 1) worse from the earliest CT scan from 9 years prior. Previous x-rays did not show any abnormality. Since then imaging has shown progressive worsening of left lower lobe hyperinflation with a mediastinal shift to the right (see Figure 2). Over the next year she continued to decline and became severely dyspneic with exertion with pursed lip breathing. Also has occasional cough but no fevers, chills, hemoptysis, orthopnea, paroxysmal nocturnal dyspnea (PND).

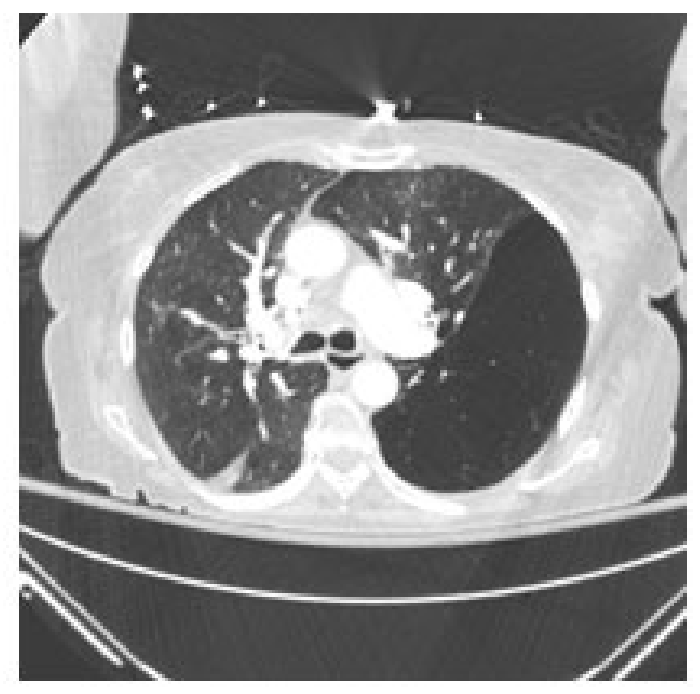

Figure 1. Axial section of CT chest (lung windows) showing marked hyperaeration in the left lower lobe

\footnotetext{
* Correspondence: Gregory C. Kane; Email: gregory.kane@jefferson.edu; Address: Department of Medicine, 834 Walnut Street Suite 650, Philadelphia, PA 19107, United States.
} 

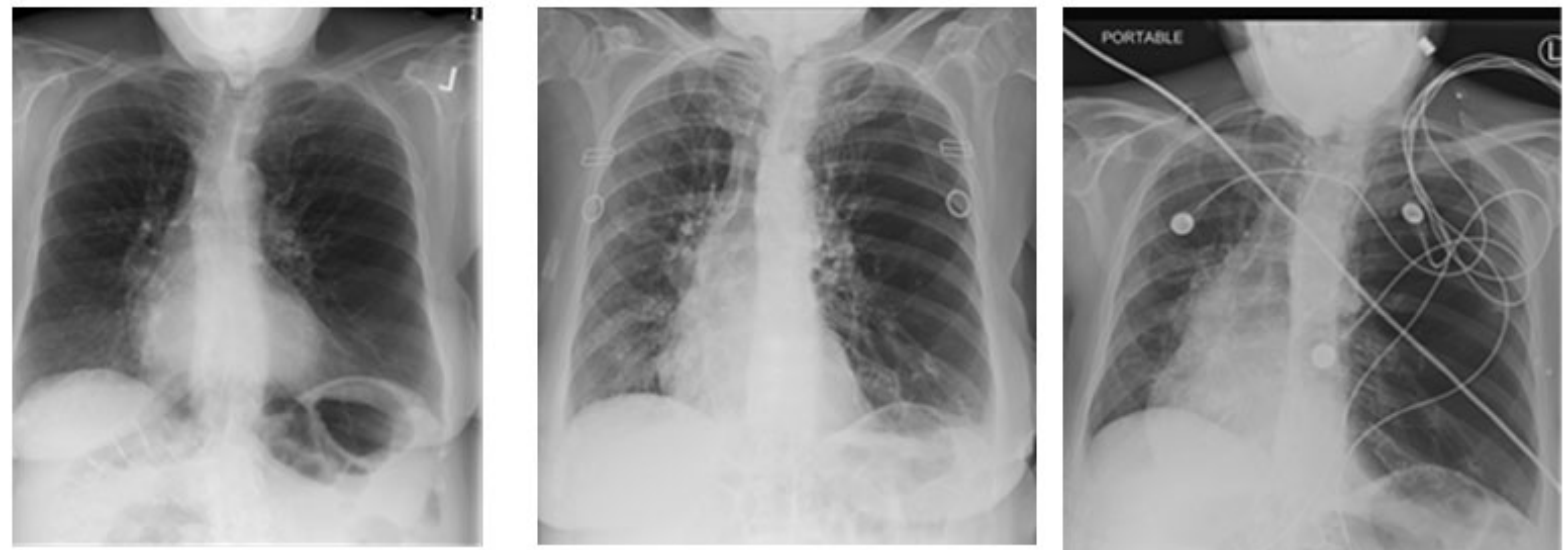

Figure 2. X-ray chest showing progressive worsening of left lower lobe hyperaeration over two years

She was a lifetime nonsmoker. There were no relevant occupational or environmental exposures. Her medications were albuterol, budesonide-formoterol, and warfarin. Pulmonary function tests showed fixed obstructive disease with FEV1 of $0.58 \mathrm{~L}$ ( $36 \%$ predicted) and severely reduced diffusion capacity. She had a normal Alpha 1 antitrypsin phenotype and $\mathrm{IgE}$ of $590 \mathrm{IU} / \mathrm{ml}(1-180 \mathrm{IU} / \mathrm{ml})$.

A bronchoscopy showed no endobronchial airway obstruction in the left lower lobe. Ventilation/perfusion (V/Q) scan showed moderately to markedly decreased ventilation in the left mid and upper lung field. Also seen gas retention at the left lower lobe, indicating airway outflow obstruction. Total perfusion for the right lung was $82 \%$ and for the left lung was $18 \%$.

The patient was evaluated for endobronchial valve placement but died of unrelated illness (sepsis related to a parotid stone) prior to intervention. Autopsy revealed severe bullous emphysema most pronounced on left lower lobe, consistent with congenital lobar emphysema.

\section{Discussion}

We present a patient with progressive unilateral left lower lobe emphysema; presumably from continued air entry into the left lower lobe without escape. Since mild hyperaeration is not visible on X-rays, it is possible that this was present since birth and not detected till she underwent her first CT scan.

Usually congenital emphysema presents with symptoms in the first 6 months in $81 \%$ of the patients. This is a very unusual presentation of progressive worsening of lobar emphysema in the eighth decade of life. There have been previously reported cases of patients being diagnosed in adulthood, however these are commonly before the end of the fourth decade of life. ${ }^{[1,2]}$ No previous cases have been reported with this finding or potential causes of worsening. Potential treatments include surgical resection and endobronchial valve replacement.

\section{CONFlicts of InTEREST Disclosure}

The authors have declared no conflicts of interest.

\section{REFERENCES}

[1] Mohammed K, Sarfraz AS, Basha K. Congenital lobar emphysema in adult: A rare case report. Respiratory Medicine CME. 2010; 3(3) 150-152. https://doi.org/10.1016/j.rmedc. 2009.09.010
[2] Humberto CS, Francis CN, Ronald SK, et al. Congenital Lobar Emphysema in an Adult. American Journal of Respiratory and Critical Care Medicine. 194(3): 377-378. PMid:27275927. https : //doi.org/10.1164/rccm.201602-0289IM 